\title{
Pontos em expansão: uma conversa com Marilyn Strathern
}

\author{
autores: Bruno Guimaráes, Luisa Girardi, Mariana Oliveira, Rui Harayama \\ tradução: Bruno GuimaráEs, Luisa Girardi, Rui Harayama \\ revisão técnica: VITOR GRUNVALD
}

Se é possível dizer que Marilyn Strathern dispensa apresentaçóes no meio acadêmico, a vastidão de sua obra e dos temas de suas pesquisas inspira no leitor a sensação de constante imprevisibilidade em relação às suas ideias. Com reflexóes inovadoras nos campos dos estudos de gênero, etnologia, propriedade intelectual, parentesco e novas tecnologias reprodutivas, para citar apenas alguns exemplos, a antropóloga visitou a Universidade Federal de Minas Gerais (UFMG), em outubro de 2009, para um ciclo de conferências ${ }^{1}$ que tornava explícita, mais uma vez, a singularidade de sua obra. Em meio às palestras proferidas, Strathern generosamente aceitou nos conceder uma entrevista para discutir o percurso mais recente de suas investigaçóes.

A sofisticação analítica da melanesianista e a relevância de seus trabalhos para o pensamento antropológico levaram-na a ser frequentemente entrevistada no sentido de debater conceitos centrais à sua produção intelectual e as implicaçóes de suas pesquisas para as várias áreas das ciências humanas. Nossa conversa percorreu um caminho menos usual, tratando antes de suas inspiraçóes, modos e condiçóes de trabalho. Uma proposta despretensiosa de realizar outro aporte à complexidade da empresa teórica e etnográfica da autora. A expectativa é que nossas questóes contribuam para a formulação de outras.

É preciso mencionar que, sem o convite feito pelo Instituto de Estudos Avançados Transdisciplinares (IEAT/UFMG), Marilyn Strathern não teria vindo ao Brasil em 2009.
Indispensáveis ao evento, nesse sentido, foram os esforços do Professor Eduardo Viana Vargas, que esteve à frente da organização das conferências realizadas. Vargas também ofertou, no segundo semestre daquele ano, a disciplina "Dádivas, Gênero e Conexôes Parciais: Leituras de Marilyn Strathern” pelo Programa de Pós-Graduação em Antropologia (PPGAN/ UFMG), contexto que propiciou o ambiente intelectual que está na origem desta entrevista. Por isso, e por todos os muitos auxílios, somos-lhe gratos. A Marilyn Strathern, por toda a gentileza e paciência, o nosso obrigado.

Da última vez que esteve no Brasil, você falou a respeito da sua trajetória desde a entrada na Universidade de Cambridge. Gostariamos de começar perguntando algumas coisas sobre antes e depois. Sobre antes: o que te levou a escolher a antropologia?

MS: Eu costumava escavar sítios arqueológicos locais quando era adolescente e me tornei bastante entusiástica em relação à arqueologia. Eu vivia nas proximidades do sul de Londres, no noroeste de Kent. Nos tempos romanos, essa região era um subúrbio: uma área cheia de casas, ladrilhada com mosaicos romanos. A partir dos treze anos, acredito, eu costumava sair para escavar aos finais de semana, normalmente aos domingos, para escapar da família. Eu me tornei muito interessada em arqueologia. Quando descobri que na Universidade de Cambridge se poderia estudar tanto arqueolo- 
200 | Pontos em eXpansão: UMa CONVERSa com Marilyn Strathern

gia quanto antropologia no primeiro ano, eu pensei que seria perfeito para mim. Mas eu sabia que não queria ser uma arqueóloga porque tinha outras ambiçóes.

De todo modo, nas aulas de história da escola secundária, estudando para as provas, nós passamos pelo século XVIII e pela Revolução Francesa; e foi preciso ler um pouco de Jean-Jacques Rousseau. Eu me tornei um tanto obcecada com a noção de sociedade. E pensei "a sociedade não existe, temos estruturas econômicas e estruturas políticas...”. Eu não formulei dessa maneira, mas lá estava o embrião dessas ideias sobre "sociedade". Eu conhecia a antropologia, mas não conseguia achar uma resposta para essas questóes. Eu tinha ideias muito grandes. Quando você é jovem, tem ideias muito grandes, não? Quanto mais velho você fica, menores suas ideias.

Agora, sobre os seus interesses mais recentes. Desde a última década, alguns temas apareceram com recorrência nos seus trabalhos: novas tecnologias reprodutivas, audit cultures ${ }^{*}$, propriedade intelectual, direito. Gostariamos de saber como esses temas foram incorporados em seu trabalho e em que medida modificaram sua produção.

1. * Nota do Revisor [N.R.]: No início dos anos 1990, os departamentos universitários ingleses passaram a ser submetidos a processos de auditoria acadêmica (Academic Audit), além de sistemas de avaliação da sua produção de pesquisa e da docência (Research Assessment Exercise - RAE e Teaching Quality Assessment - TQA). Tais processos geram uma pontuação que determina, dentre outras coisas, o montante de investimento público em cada universidade. Ao longo dessa mesma década, Strathern fez esforços no sentido de promover reflexóes sobre o que passou a ser chamado de audit cultures e organizou, em 2000, o livro Audit Cultures: Anthropological studies in accountability, ethics and the academy.
MS: Houve um período em que eu ficava entre o Reino Unido e a Papua-Nova Guiné. Quando finalmente regressei ao Reino Unido - eu era coordenadora do Departamento de Antropologia Social da Universidade de Manchester -, repentinamente, recebi um telefonema de uma pessoa que vinha trabalhando com novas tecnologias reprodutivas. Isso foi em 1987. Ela perguntou qual seria a opinião dos antropólogos sobre a doaçâo de óvulos entre irmãs. Em outras palavras, no contexto das doações de gametas, o que os antropólogos diriam se os óvulos fossem compartilhados entre irmâs? E eu disse: "a antropologia não tem nada a dizer, porque até onde eu sei a antropologia nunca pensou sobre essas coisas". E aquela pergunta ficou na minha cabeça. Nesse momento, era o início das discussões sobre o assunto que começou a ser trabalhado principalmente pelas escritoras feministas. Eu, então, li uma narrativa sobre tecnologias reprodutivas e fiquei fascinada.

Em 1989-1990, organizei com colegas uma pesquisa nessa área e fiz um estudo sobre parentesco. Parecia-me que as questóes colocadas pelas novas tecnologias reprodutivas - que eram questóes sobre quem era a mãe de verdade, sobre quão longe era possível interferir na natureza não eram questôes relacionadas com família que era o conceito nativo. Elas se relacionavam com um conceito antropológico: eram sobre parentesco! E, repentinamente, achei que a antropologia tinha algo a dizer que náo poderia ser apreendido pelos modelos nativos de família e parentes. Eu também fiquei fascinada porque, subitamente, qualquer um podia dar uma opiniáo. De fato, aqui estava o povo inglês falando sobre natureza e cultura! Ora, nós lemos sobre isso em Lévi-Strauss, mas aqui eram os ingleses debatendo natureza e cultura. Para mim era fascinante.

Durante minhas leituras nessa área, deparei-me com uma narrativa sobre um caso nos 
Estados Unidos. Eu não sei como vocês percebem os Estados Unidos no Brasil, mas na Inglaterra nós os vemos como um lugar de excesso. Tudo o que é feito é levado ao excesso. Especialmente os advogados estadunidenses que levam as coisas aos seus limites. Um exemplo é um advogado que estava defendendo as reivindicaçóes de um casal que havia encomendado uma barriga de aluguel para gestar seu filho genético. E o que ele fez - esse é o ponto a ser ressaltado - foi estabelecer uma analogia entre a concepção mental e a concepção biológica que, em inglês, obviamente, é a mesma palavra. A ideia é que a mãe que reivindicava a criança expressava tanto instinto maternal quanto a mãe que gestou a criança. Essa era uma concepção mental. A partir disso, o advogado esboçou uma analogia com a propriedade intelectual. E aí estão os advogados realmente levando as coisas ao extremo!

De todas as formas, essa foi a ligação: das novas tecnologias reprodutivas para a propriedade intelectual. E eu pensei: "o que é isso? o que está acontecendo?”. E comecei a ler um pouco sobre propriedade intelectual. Eu sabia que durante a década de 1990 existiram diversos movimentos indígenas que tentaram entender se a propriedade intelectual realmente resolveria seus questionamentos sobre como proteger intangíveis; sobre como proteger, por exemplo, a propriedade cultural, os padróes gráficos, o conhecimento tradicional e assim por diante. $\mathrm{E}$, então, me dei conta que existiam diversos estudantes que haviam trabalhado na Melanésia - James Leach, Tony Crook, Andy Holding, Melissa Demian - e que eu também tinha boas relações com colegas como Eric Hirsch e Karen Sykes. Compreendi que, se algum dia haveria um momento em que poderíamos fazer um projeto juntos, possivelmente o momento era aquele. E pensei, junto com Eric Hirsch - tam- bém coordenador do projeto ${ }^{2 *}$ - que seria muito interessante voltar para a Papua-Nova Guiné nesse momento quando os direitos de propriedade intelectual estavam sendo desenvolvidos pela Organização Mundial do Comércio através do Acordo Geral de Tarifas e Comércio ${ }^{3 * *}$. Se vocês examinarem $O$ Gênero da Dádiva, verão que, nessa obra, eu expurgo, oblitero o conceito de propriedade. Assim, era muito interessante regressar à Papua-Nova Guiné precisando utilizar a palavra "propriedade". De um ponto de vista analítico, era muito conveniente afirmar "eu não vou fazer o uso da palavra 'propriedade”". Mas se você está lidando com o discurso internacional, não é possível evitá-la. Então, ali estava eu voltando para a Papua-Nova Guiné com esse conceito que, em outras circunstâncias, eu não teria trabalhado. Foi daí que o meu projeto sobre propriedade intelectual na Papua-Nova Guiné surgiu.

É preciso entender, contudo, que não estou falando sobre as livres escolhas de uma acadêmica que pesquisa o que bem entende, nem sobre encontrar oportunidades para pesquisa. Estou falando sobre uma atmosfera institucional na qual você deve, constantemente, conceber temas de pesquisa. A minha busca por estudantes que haviam trabalhado na Papua-Nova Guiné e o encontro com meus colegas não surgiu de um pensamento do tipo "essa é uma boa ideia", mas sim "aqui tem um recurso

2. * [N.R.]: Strathern se refere ao projeto de pesquisa Property, Transactions and Creations: New Economic Relations in the Pacific, coordenado por ela e pelo professor Eric Hirsch em colaboraçáo com o National Research Institute em Port Moresby entre 1999 e 2002. Alguns resultados dessa pesquisa foram publicados no livro Transactions and Creations. Property Debates and Stimulus of Melanesia, editado por eles em 2004. Mais adiante, o projeto é retomado nesta entrevista.

3. ${ }^{* *}$ [N.R.]: Em inglês, General Agreement on Tariffs and Trade (GATT). 
202 Pontos EM EXPANSÃo: UMA CONVERSA COM Marilyn Strathern

e eu devo utilizá-lo”. De fato, grande parte da minha vida acadêmica foi governada por demandas institucionais para fazer pesquisa. Logo, aqui não estamos falando de um espírito livre.

Isso me leva ao último tema: direito. Em 1964, quando estive pela primeira vez nas Terras Altas da Papua-Nova Guiné, encontrei uma curiosa forma de vida pública em torno da qual regularmente $-\mathrm{e}$, certamente, aos finais de semana - as pessoas se reuniam. Era possível observar grupos de pessoas conversando muito atenciosamente, outras pessoas se movimentando, outras sentando. Esses eram os chamados "tribunais": as pessoas estavam fazendo tribunais de direito, estavam imitando os administradores. As pessoas locais estavam assumindo para si, por assim dizer, o que os seus administradores coloniais haviam dito: "vocês precisam obedecer a lei". E, é claro, os administradores achavam que esses tribunais eram ilegais. Aos olhos do direito formal, as pessoas estavam fazendo o direito com suas próprias mãos e elas não deveriam fazer isso. Eu fiquei bastante interessada pelas práticas de disputa em geral, mas também pelo fato de que, invariavelmente, a pessoa no centro do problema era uma mulher. Nesse período, elas estavam no centro da maioria dos problemas porque eram as mulheres que ligavam os homens. Os debates eram constantes entre os homens, mas eram as mulheres que, de alguma maneira, estavam no caminho: elas interferiam nas relaçóes entre os homens ou elas desejavam divorciar-se de um homem, o que implicava na quebra das relaçóes masculinas. Foram esses tribunais que me conduziram às questóes relativas ao direito e ao gênero. Sem dúvida, busquei o direito durante todo o tempo. Esse tema sempre me pareceu interessante.

Atualmente, os temas de pesquisa do Departamento de Antropologia Social de Cambridge são: "novas formas de parentesco e reprodução familiar", "bioética", "as implicaçóes sociais da tecnologia" e "criatividade cultural", dentre outros. Em outras palavras, as pesquisas atuais não parecem lembrar um departamento em que a imagem clássica da antropologia social britânica emergiu. Onde você situa seu trabalho nesta mudança e como você percebe o impacto de suas pesquisas na antropologia social britânica e, mais especificamente, em Cambridge?

MS: Esta é uma questão muito interessante. Entre os departamentos do Reino Unido, o de Cambridge é considerado tradicional. E o motivo disso é que, no que tange ao ensino na graduação, o departamento prepara o estudante com muito material tradicional, pelo menos nos dois primeiros anos. E é claro que ocorrem debates infindáveis, que eu não sei se existem no Brasil. Incluímos Marx, Weber, Durkheim? Eu não sei. Sabemos que vamos colocar um pouco de Evans-Pritchard, um pouco de Malinowski, de Meyer Fortes, e assim por diante. Mas onde estarão Marx, Weber e Durkheim? Passaremos pelo funcionalismo, estruturalismo, estrutural-funcionalismo? Então, todo ano, há uma discussão sobre o currículo. Mas se você olhar o programa da graduação, ele seria corretamente reconhecido como clássico. Porém, isto não impede que as pessoas, sobretudo na pesquisa, façam todo tipo de coisa que nunca esteve no repertório clássico, mas que não é contrária a ele. Em outras palavras, essas pesquisas não estão em oposição ao repertório clássico, são suas extensões. Devo frisar que esses são antes tópicos de pesquisa do que de ensino, apesar de entrarem no currículo nos segundo e terceiro anos. Mas eu não os vejo como contrários ou em oposição aos temas clássicos, eu os vejo como seus desdobramentos. Isto é mais evidente na área das tecnologias reprodutivas, pois, durante muito tempo, o parentesco era considerado uma das questóes mais obscuras, 
complicadas, entediantes e óbvias. E, de fato, foram as novas tecnologias reprodutivas, com todo seu encanto, que reviveram o interesse no parentesco. Praticamente todos os departamentos de Antropologia Social no Reino Unido ensinam novas tecnologias reprodutivas. E, é claro, isso leva a um resgate: muitas pessoas voltam ao Morgan, retornam aos trabalhos iniciais. De fato, isso revive o interesse geral por parentesco.

Outra coisa que fazemos na Universidade de Cambridge - e sobre a qual insistimos fortemente - é dar preferência a estudos originais. Durante o terceiro ano, os estudantes precisam fazer uma disciplina sobre uma região particular: pode ser o Sul da Ásia ou o Oriente Médio, a Melanésia, a África Ocidental ou outro local qualquer. Insistimos que os alunos se aprofundem nas etnografias de uma região específica. E, a partir daí, você pode fazer o que quiser, pois estão disponíveis as teorias clássicas e os trabalhos contemporâneos, tudo reunido.

Nós também gostariamos de saber um pouco mais sobre alguns de seus trabalhos anteriores. As próximas perguntas serão sobre temas especificos a eles. "Property, Transactions and Creations: New Economic Forms in the Pacific" foi um projeto de pesquisa relacionado a algumas reflexóes presentes em suas últimas publicaçóes. Você poderia nos falar sobre este projeto e como ele lhe ajudou a pensar sobre as práticas melanésias locais em um contexto global?

MS: Eu tive um ano sabático. Isto foi muito relevante. Foi o primeiro ano sabático que tive em muito tempo. E não fui à Papua-Nova Guiné. $\mathrm{O}$ que fiz foi ler livros jurídicos. E fiquei atordoada com o que havia naqueles livros, com os pressupostos que eles utilizavam! Eu não sou especialista, não fui muito longe e nunca falaria na presença de advogados. Mas, como antropóloga, fiquei estupefata. No entanto, meus colegas foram todos a campo e nós trouxemos para o projeto Lawrence Kalinoe, um jurista da Papua-Nova Guiné. Ele foi magnífico! Veio a Cambridge e não estava conosco há muito tempo - cerca de seis semanas - quando falou: "Hum... Interessante. Eu sei sobre o que a antropologia trata. Ela trata de relaçóes, não é?”. Havia antropólogos na Papua-Nova Guiné, o que é muito importante, pois não seria possível organizar um projeto de pesquisa sem levar em consideração os acadêmicos locais. Lawrence foi o jurista do projeto e havia também Jacob Simet. Este último foi um dos poucos antropólogos que foram, de fato, formados em Camberra, na Austrália e um dos poucos também a tentar uma vida acadêmica em Porto Moresby.

É preciso compreender o quão difícil é ser acadêmico em um país de terceiro mundo em que existem todos os tipos de pressóes e problemas. Eu tiro meu chapéu para aqueles que se engajaram, nesse contexto, em alguma forma de vida acadêmica. Não havia, porém, muitos outros. Eram esses dois, ao lado de outras pessoas com as quais conversávamos, mas não havia muitos outros que queriam saber o que fazíamos. Não acho que isto de fato importava, em parte porque esses dois influenciaram diretamente a legislação, ou melhor: o modelo jurídico que os estados das Ilhas do Pacífico adotaram em relação à proteção das "expressôes da cultura”, como eles as chamavam.

Para mim, ou para meus colegas que fizeram trabalho de campo, isso gerou muitas discussóes interessantes. Muitas delas foram um impulso para outros projetos. Eu estava impressionada pelo fato de que nossos colegas da Papua-Nova Guiné eram gratos por não sermos consultores, não sermos ONGs e não estarmos tentando lhes explicar nada. Tudo o que fazíamos era dizer: "olhe, isto daqui também pode ser pensado de outra forma, existem outros vocabulários". E, para mim, isto foi tudo o que fizemos. 
204 | Pontos EM EXPansão: uma conversa com Marilyn Strathern

Mas isto vai desaparecer sem deixar rastros, não vai aparecer, não é algo que seja possível rastrear. Eu não posso demonstrar em uma avaliação acadêmica o que eu produzi e não há como apontar os fatos: "bem, na verdade, eu acho que foi nessa ou naquela conversa que aconteceu”. Não existe uma forma pela qual isto possa ser apreendido, medido ou contabilizado. O que sei é que estamos felizes de tê-lo feito. E se eu, alguma vez, fiz algo que valeu a pena - e eu acho que fiz nesse projeto - foi porque era tudo o que queriam. Eles só queriam ser convidados para participar de conversas em que as pessoas não utilizavam nenhuma das linguagens burocráticas com as quais eles estavam acostumados. Quero dizer, eles são capazes de fazer suas próprias invençóes, seguirem seus caminhos, e assim por diante.

As perguntas seguintes abordam de forma mais especifica alguns conceitos ou ideias que aparecem em seus escritos. Gostariamos de perguntar, inicialmente, como você percebe os conceitos euro- americanos de história e mudança? Você os considera apropriados para pensar a Melanésia?

MS: Essa é, realmente, uma questão profunda. Ela parece simples, mas, na verdade, é uma questão realmente profunda. Preciso dizer que tenho um filho historiador e, portanto, não deveria ser muito hesitante em relação à história. Mas eu nunca compreendi a história, embora seja possível encontrar isso no site da Universidade de Cambridge: Antropologia Histórica. Acho que meus problemas começaram logo no início, quando estava fazendo graduação. Precisei ler os escritos de Evans-Pritchard sobre antropologia e história e não conseguia ver o sentido disso. Certa vez, escrevi um artigo chamado "No culture, no history", no qual relacionei a história com algum sentido que as pessoas precisam ter sobre elas próprias, em que há alguma continuidade com sua vida coletiva. Argumentei que, no contexto em que não há um conceito de sociedade, de cultura ou de uma vida abstrata separada da vida de pessoas individuais, não há nada sobre o que se ter uma história. Então, não estou respondendo a pergunta de vocês muito bem porque tenho problemas com esse conceito.

Sobre mudança - e esta é uma questão interessante -, uma das conclusóes a que cheguei em O Gênero da Dádiva é que as pessoas estão constantemente alternando entre diferentes modalidades, entre diferentes tempos. Tomando os homens como exemplo, em um momento, a questão é pensar no clã, na mentalidade do clâ, em outro, é pensar a si próprio como imerso dentro em um nexo individual de relaçôes que ninguém mais possui. Há uma alternância entre os estilos de sociabilidade ${ }^{4 *}$ pessoas se reunindo e pessoas se separando - de

4. * [N.R.]: No clássico debate sobre a "obsolescência do conceito de sociedade" (Ingold et al., 1996), a noção de socialidade é enfatizada por alguns(as) antropólogos(as) britânicos(as) tanto por não figurar como uma entidade autônoma que estabeleceria relaçóes com sua antinomia completar, o indivíduo, quanto por romper com a lógica que equaliza sociedade e grupo (cf., adicionalmente, Strathern, 1992a). Este último conceito se refere a uma "matriz relacional que constitui a vida das pessoas" (Strathern et al., 1996a, p. 64). A questão é de extrema relevância já que, tal como explicita Strathern nesta entrevista, as modalidades ou tempos da vida social entre as quais as pessoas estáo constantemente alternando apontam para dois tipos ou momentos de socialidade - um de caráter plural e outro singular -, ora replicação, ora substituição. Em outra entrevista, concedida a Eduardo Viveiros de Castro e Carlos Fausto (1999b), a autora faz advertências para o problema da redução antropológica da socialidade à sociabilidade (quando este termo se associa ao que está subsumido ao conceito obsoleto de "sociedade") no tratamento de grupos que não operam a partir da persuasão inerente ao discurso euro-americano. Nesse sentido, é possível que a autora esteja se referindo aqui a essa matriz relacional que constitui a vida das pessoas em lugar do termo sociabilidade. 
modo que elas produzem estados alternativos, tais como iniciados e pré-iniciados; ou como os momentos em que se revela e se esconde o mundo. E as pessoas estáo constantemente alternando. Outro exemplo é quando eu falo sobre a ideia de que é possível ver a terra de dois modos diferentes. Essa era a prática habitual: você está em um estado, mas está prestes a entrar em outro. $\mathrm{E}$, nesse contexto, não há a percepção de uma sociedade estática, de modo que alguém possa pensar em mudança como algo que fará uma sociedade estática transformar-se em uma sociedade dinâmica. Já estamos lidando com uma sociedade que se move constantemente entre posiçóes. É claro que essas posiçóes são previsíveis, mas penso que é possível falar em mudança no sentido de que essas pessoas não possuem apenas esses momentos oscilantes. Elas são o que denomino “modernas", isto é, percebem-se como fazendo uma escolha, tomando um caminho e abandonando o outro. Elas se pensam como assumindo as práticas relativas ao exercício do direito, como no caso em que organizam tribunais. Elas se pensam como assumindo o mundo. Elas são incrivelmente livres de qualquer constrangimento frente à tecnologia. Ninguém as ensinou que os brancos possuem três mil anos de civilização. Elas não têm ideia. Elas apenas veem uma rota à frente e não tem nenhuma inibição com a tecnologia. Elas se perceberiam como tão cosmopolitas, operando no mundo tal como ele é - com seus telefones celulares e todo o resto - como qualquer outra pessoa. Este é o mundo em que vivem. E isso é tudo que precisam saber.

Em diversos momentos, você se mostrou preocupada com as limitaçóes do método comparativo na prática antropológica. Aparentemente, um dos principais constrangimentos associados à comparação estaria na pressuposição de paralelos naturais entre os termos comparados. Esse constrangimento poderia engendrar uma série de problemas como, por exemplo, a extensão do conceito de sociedade e cultura para contextos não-ocidentais. O que, então, deveríamos comparar?

MS: Creio que vocês tocaram em um ponto que é absolutamente crucial há algum tempo. Como sabem, a antropologia comparativa tradicional do tipo que Jack Goody realizou, por exemplo, ou as comparaçóes que foram levados a cabo pelo Human Relations Area Project, não tem sido feitas há muito tempo ${ }^{2}$. $\mathrm{O}$ que ocorreu foi que - e, aqui, estou falando sobre o Reino Unido, os Estados Unidos e alguma antropologia europeia - iniciou-se um período de tremenda sofisticação da monografia etnográfica. Algumas obras excelentes surgiram no último quarto do século $\mathrm{XX}$, obras realmente requintadas. É claro que essas obras dificilmente eram comparativas. Mas eram primorosas porque se voltavam para si mesmas e estavam bastante afinadas. Acho que disse, no começo de $O$ Gênero da Dádiva, que o problema não é a falta, mas o excesso de boas etnografias.

Em alguma medida, o conceito de globalização apareceu e tomou o lugar da comparação. Porque, se é possível ver povos de todos os locais como suscetíveis a circunstâncias ou ideaçôes econômicas e institucionais similares, então se tem uma referência para pensar o que está acontecendo. A partir daí, é claro, surgem novas invençôes analíticas e outros arranjos.

Acredito em um tipo particular de comparação. Não é realmente uma comparação, mas poderíamos chamá-la assim. Se me pressionassem e perguntassem "como definir cultura?", provavelmente eu responderia que se sabe que se está no limite de uma cultura particular ou de uma configuração cultural ou de uma formação cultural quando determinadas analogias deixam de fazer sentido. Em outras palavras, o 
206 Pontos EM EXPANSÃo: UMA CONVERSA COM Marilyn Strathern

que definimos como cultura é a maneira pela qual as próprias pessoas estabelecem analogias, contrastes ou a maneira como elas comparam diferentes elementos da sua vida com outros elementos. Apenas a título de exemplo, meu livro After Nature - que trata sobre o parentesco inglês - também é uma crítica à ideologia conservadora que coloca o indivíduo no centro da vida política. Eu queria fazer a pergunta: "se há algo como uma cultura inglesa, então, onde estamos nós, indivíduos, dentro desta cultura?”. Em outras palavras, aquele indivíduo político ressoa e faz sentido porque indivíduos estão sendo produzidos em outros lugares. E eu descrevi isso com o parentesco inglês: o sistema de parentesco produz indivíduos. Eu estava fazendo uma analogia entre o individualismo como tema político e os indivíduos como o produto de sistemas de parentesco. Mas as próprias pessoas também estabelecem analogias. $\mathrm{Na}$ área das novas tecnologias reprodutivas, por exemplo, as pessoas estabeleceriam analogias entre a doação de gametas e a doação de órgãos ou de sangue.

Mencionei que nas analogias existem artefatos culturais. E é possível produzir com analogias. Suponhamos que se está descrevendo um conjunto de circunstâncias. E é preciso estar atenta à linguagem da descrição enquanto um recurso. Na minha cabeça, certamente, estão muitos relatos etnográficos. Posso decidir que, na realidade, quero descrever uma sociedade ' $X$ ' na Papua-Nova Guiné - estou usando a palavra sociedade - fazendo uso de conceitos derivados da sociedade ' $Y$ '. Em outras palavras, posso querer olhar uma configuração social particular através de olhos bem diferentes. E eu não quero chamar isso de comparação, pois é algo muito mais semelhante ao ato de traçar uma analogia. Eu não preciso utilizar a noção de propriedade intelectual como uma analogia para considerar proprietários de terra. Mas pos- so escolher isso como um modo de descrição. Não estou dizendo que a terra é propriedade intelectual, estou dizendo: "usando essa linguagem, quão longe a analogia com a propriedade intelectual pode nos levar para entender o que está acontecendo?”. Isso, então, não é comparação, mas algo parecido.

Apesar de pertencerem a duas regióes etnográficas distintas, aparentemente podemos estabelecer conexóes entre os modos de conhecimento melanésio e amazônico, tais como descritos por alguns antropólogos. Em que termos poderíamos pensar em uma "Melazônia" * e na extensão dos conceitos de "perspectivismo" e "troca transgenderificada" de uma regiâo para outra?

MS: Acredito que o que é realmente interessante nos modos de conhecimento melanésio e amazônico é que ambos fazem algo com os modos de pensar euro-americanos. Eles o colocam em xeque. E nesse aspecto são bem similares. Existem, é claro, enormes diferenças em toda a questáo das trocas de riquezas, por exemplo. Existem consideráveis diferenças se quisermos tomar as duas áreas como regióes etnográficas. Eu diria, ainda assim, que as demandas que esses modos de conhecimento colocam para os antropólogos são bastante similares. Nesse sentido, a "Melazônia" pode ser considerada um campo epistêmico.

O perspectivismo é uma dessas noções esclarecedoras que parecem ser a solução de muitos problemas e questôes, e acho que nós

5. * [N.R.]: Melazônia é um lugar imaginário pressuposto pelos esforços comparativos de alguns antropólogos no livro Gender in Amazonia and Melanesia. An Exploration of the Comparative Method, organizado por Thomas Gregor e Donald Tuzin. O termo é sugerido por Stephen Hugh-Jones em seu artigo no livro e, então, adotado por alguns autores para destacar algumas similaridades entre Amazônia e Melanésia. 
devemos ser infinitamente gratos que este conceito tenha sido articulado da maneira como tem sido. Mas vocês devem saber que os melanésios simplesmente não estão preocupados com o conceito que, na Amazônia, é traduzido por "humano". E, parcialmente, isso se deve ao fato de que não há propensão para perceber humanos e animais (ou outras formas) como transformações uns dos outros. Eventualmente, é claro, na mitologia, por exemplo, as pessoas aparecem sob diferentes disfarces - como espíritos, por exemplo. Mas não há conversão sistemática de pessoas conforme o crescimento, o casamento e a predação que ocorrem durante um ciclo de vida, como observamos em muitos contextos amazônicos.

O que as pessoas fazem, realmente, é se diferenciar o tempo todo: elas diferenciam um mundo e outro e mais um. Trata-se de uma constante sobreposição de diferenciações. As pessoas se diferenciam por meio de regras matrimoniais, através das trocas, através do gênero. Na Papua-Nova Guiné, o gênero - que, na Amazônia, não produz nada, nem explica muito - torna-se um dos signos pelos quais as pessoas dizem a si mesmas que produziram uma diferença criativa. Se eu quisesse transpor a noção de perspectivismo para a Melanésia, portanto, estaria inclinada a afirmar que o seu análogo poderia ser encontrado nos tipos de posiçóes que as pessoas se colocam umas em relação às outras.

Acho que, em um de meus trabalhos, uso um exemplo muito óbvio, proveniente da esfera do parentesco: tem-se uma pessoa, o pai desta pessoa e o irmão da mãe desta pessoa. Se tomarmos a perspectiva do pai, esta pessoa será percebida como um afim; se tomarmos a perspectiva do irmão da mãe, então, esta pessoa será um consanguíneo. Esses termos não existem diagramaticamente, tal como poderíamos desenhá-los [em um quadro genealógico]. Eles são inerentes ao modo como as pessoas habitam seus corpos, então seria possível ver o pai de alguém enquanto pai de alguém ou o pai de alguém enquanto o irmão da mãe de alguém. $\mathrm{E}$ isto produz duas constelaçôes bem diferentes da noção de perspectivismo. É possível, portanto, tomá-la de empréstimo de maneira limitada. Mas seria outra analogia.

Eduardo Viveiros de Castro é um dos autores de maior relevância nos estudos contemporâneos sobre a Amazônia e vem, cada vez mais, dialogando com seus escritos. Em que medida seus trabalhos se separam e se aproximam dos trabalhos de Viveiros de Castro?

MS: A obra de Viveiros de Castro é muito interessante porque penso que ele atende àquilo que descrevi anteriormente: a capacidade do pensamento amazônico de colocar em xeque e se infiltrar sob a pele. Isso tem lhe garantido acesso a muitas questões teóricas. E ele é um brilhante teórico nesse sentido.

A maneira mais radical em que eu me afasto do que ele faz é que eu não cuido das minhas genealogias teóricas. No meu trabalho, é possível encontrar referência a um ou outro antropólogo e melanesianista; pois, quando eu trabalho, gosto de ter poucas coisas ao meu redor. Eu faço com o que tenho. E tenho diversos motivos para trabalhar assim.

Um motivo é que realmente penso que investir demais em outras projeçóes teóricas pode ser um fardo, porque se acaba reinventando a posição de onde elas vêm. De fato, eu faço um tipo de teorização inversa, na qual eu mantenho cartóes e, cada vez que eu encontro algo parecido com alguma coisa que eu tenha escrito, faço uma anotação. Então, organizo estas informaçóes como em um tipo de genealogia teórica post-hoc de coisas as quais eu poderia ter me referido. O que é bom, porque eu produzo, tenho o meu campo delimitado. 
208 Pontos em eXpansão: UMA CONVERSA COM Marilyn Strathern

Não sei se vocês conhecem uma famosa escritora inglesa chamada Jane Austen, mas é um pouco como Jane Austen: ela escrevia a partir de um universo delimitado, sobre o qual, às vezes, penso. Não estou dizendo que eu seja "austeniana”. É claro que eu não diria isto, mas eu compreendo o que ela estava fazendo. $\mathrm{O}$ que quero dizer é que eu não posso fazer o tipo de trabalho que Viveiros de Castro realiza ao abrir campos teóricos - algo que eu acho extremamente estimulante de escutar, mas que não conseguiria fazer.

Para encerrar a entrevista: tanto em The Relation quanto em Kinship, Law and the Unexpected, você afirma que a noção de relação foi recorrentemente utilizada como uma ferramenta antropológica. Como evitar que o conceito de relação não acabe sendo utilizado de maneira similar à noção de cultura, expandindo-se indefinidamente em sentido e perdendo seu potencial analítico?

MS: Essa é uma ótima pergunta para terminar porque eu diria que cheguei à conclusão de que, afinal de contas, a relação e a análise relacional não podem fazer mais do que apontar as relaçóes. E acabamos, efetivamente, em um ponto de eterna expansão. Não diria, entretanto, que há perda de potencial analítico. Essa não é uma consequência. Tudo o que isso significa é que você nunca sairá das relações que produziu. Obviamente, isso é uma fantasia histórica. Mas uma das coisas que surgiu com o Iluminismo e com o advento das ciências foi que, ao dispensar a faculdade da fé ou de qualquer outra coisa como uma causa explicativa, tudo o que resta é descrever o mundo em relação a si mesmo. Não há nenhum outro mecanismo para descrever o mundo que náo o de colocar as coisas em relaçóes, quer você esteja observando pedras geológicas, quer você esteja medindo substâncias em um tubo de ensaio, quer você esteja calculando a distância das es- trelas... O que quer que você esteja fazendo, a única posição que você pode ocupar é aquela do dicionário: você só pode definir uma palavra usando outras palavras que estão em outros locais do dicionário. E, para mim, essa é a condição que define a antropologia e que torna explicitamente interessante a importância das relações para a revolução científica. Mas ela não pode te levar a nenhum outro lugar.

\section{Notas}

1 O ciclo de conferências ocorreu na Universidade Federal de Minas Gerais (UFMG) entre os dias 20 e 24 de outubro de 2009, com o apoio do Instituto de Estudos Avançados Transdisciplinares (IEAT), da Fundação de Desenvolvimento da Pesquisa (FUNDEP), da Faculdade de Filosofia e Ciências Humanas (FAFICH), do Programa de Pós-graduação em Antropologia (PPGAN) e do Laboratório de Antropologia das Controvérsias Sociotécnicas (LACS). As conferências proferidas na Cátedra IEAT /FUNDEP Humanidades, Letras e Artes de 2009 foram nomeadas com os títulos a seguir: "Land as intelectual property"; "Sharing, stealing and borrowing simultaneously"; "Authors and owners: issues in the dissemination of knowledge".

2 Strathern se refere a comparaçóes detalhistas entre atributos semelhantes de populaçôes vizinhas, buscando verificar as implicaçóes de eventuais distinções. Nos termos em que ela colocou, durante a entrevista: "[Goody] comparava duas diferentes sociedades do oeste da África e, então, as pequenas diferenças entre pais e filhos que cultivavam juntos e irmãos de diferentes idades que faziam o mesmo, analisando como estas variaçóes tinham grandes repercussóes sobre como os funerais eram realizados, que, por sua vez, tinha consequências na herança da terra." Sobre o Human Relations Area Project, Strathern explicou: "um modelo de comparação no qual você isola traços, práticas particulares e diversos exemplos dessas práticas da maneira que pode e, a partir disso, tenta reproduzir a ecologia e o contexto destas práticas". 


\section{Referências bibliográficas}

GREGOR, Thomas; TUZIN, Donald (eds.). Gender in Amazonia and Melanesia: an exploration of the comparative method. Berkeley and Los Angeles: University of California Press, 2001.

HIRSCH, Eric; STRATHERN, Marilyn (eds.). Transactions and creations: Property Debates and the Stimulus of Melanesia. Oxford: Berghahn Books, 2004.

HUGH-JONES, Stephen. "The gender of some amazonian gifts: An experiment with an experiment." In: GREGOR, Thomas \& TUZIN, Donald (eds.). Gender in Amazonia and Melanesia: an exploration of the comparative method. Berkeley and Los Angeles: University of California Press, 2001. p. 245-278.

INGOLD, Tim. "Introduction: The Concept of Society Is Theoretically Obsolete”. In: INGOLD, Tim (ed.). Key debates in Anthropology. London: Routledge, 1996. p. 57-59.

STRATHERN, Marilyn. The Gender of the Gift: Problems with Women and Problems with Society in Melanesia. Berkeley, Los Angeles: University of California Press, 1988 [Versão em português: Campinas: Editora da Unicamp, 2006.].

. "Parts and wholes. Refiguring relationships in a post-plural world”. In: KUPER, Adam (ed.). Conceptualizing society. London: Routledge, 1992a. p. 75-104.

. After Nature: English Kinship in the Late Twentieth Century. Cambridge: Cambridge University Press, 1992b.
The relation: issues in complexity and scale. Cambridge: Prickly Pear Press.

. "The Concept of Society Is Theoretically Obsolete: For the Motion (1)". In: INGOLD, Tim (ed.). Key debates in Anthropology. London: Routledge, 1996a. p. 60-66.

"No culture, no history". In: TELBAN, Borut (ed.). Multiple identities. Ljubljana: Slovene Anthropological Society, [1984] 1996b. p. 118-136 (Anthropological Notebooks, Special Issue; v.2, 1).

. Property, Substance, and Effect: anthropological essays on persons and things. London \& New Brunswick: The Athlone Press, 1999a.

"No limite de uma certa linguagem". Mana: Estudos de Antropologia Social, v. 5, n. 2, p. 157-175, $1999 \mathrm{~b}$.

(ed.) Audit culures. Anthropological studies in accountability, ethics and the academy. New York: Routledge, 2000.

. Kinship, law and the unexpected: relatives are always a surprise. Cambridge: Cambridge University Press, 2005. entrevistatores

tradutores

revisão técnica
Bruno Guimarães, Luisa Girardi, Mariana Oliveira, Rui Harayama Mestrando em Antropologia Social / PPGAN - USP

Bruno Guimarães, Luisa Girardi, Rui Harayama

Mestrando em Antropologia Social / PPGAN - USP

Vitor Grunvald

Doutorando em Antropologia Social / PPGAN - USP

Recebida em 27/07/12

aceita para publicação 09/12/12 